Ethiopian Journal of Environmental Studies \& Management 7(5): 499 - 507, 2014

ISSN:1998-0507

doi: http://dx.doi.org/10.4314/ejesm.v7i5.4

Submitted: May 12, 2014

Accepted: August 04, 2014

\title{
INVESTIGATION ON THE ACTIVITIES OF YEASTS IN THE POST HARVEST SPOILAGE OF SWEET POTATO (Ipomea batatas L.)
}

OLADOYE, C.0.,1 CONNERTON, I.F., 1 *KAYODE, R.M.0. ${ }^{2}$ AND OMOJASOLA, P.F. 3

${ }^{1}$ Division of Food Sciences, School of Biosciences, The University of Nottingham, Sutton Bonington Campus, Loughborough, LE12 5RD

${ }^{2}$ Division of Food Preservation, Microbial Biotechnology and Toxicology, Department of Home Economics and Food Science, University of Ilorin, P.M.B 1515, Ilorin, Nigeria

${ }^{3}$ Department of Microbiology, Faculty of Life Sciences, University of Ilorin, P.M.B 1515, Ilorin, Nigeria

\begin{abstract}
Postharvest losses due to the activities of indigenous microorganisms occur in many crops such as sweet potato (Ipomoea batatas) which result in heavy financial losses for farmers. Correct identification of the pathogen responsible for postharvest infection is central to adopting an appropriate control strategy. Samples of sweet potato tubers were purchased from the local market and stored at three temperatures: $13^{\circ} \mathrm{C}, 21^{\circ} \mathrm{C}$ and $29^{\circ}$ for four weeks. Spoilage yeasts were isolated from the tuber samples. The isolates were characterized using yeast genomic DNA extraction, polymerase chain amplification of rRNA and sequence determination. The yeasts were identified on the basis of the 26S rDNA. Six yeast species were identified as Rhodotorula mucilaginosa, R. minuta, Pichiaguilliermondii, P. anomala, Sporobolomyces marcillae and Saccharomycopsis fibuligera. The results indicated that the D1 and D2 domains of the 5' end of the 26S rDNA showed a high degree of interspecies sequence variation for the isolates. Two of the yeasts; $P$. anomala and $R$. minuta were selected for further investigations namely pathogenicity testing and assay for extracellular enzymes. Results of the pathogenicity tests showed that $P$. anomala and $R$. minuta were clearly able to infect the sweet potato tubers. The results of the enzyme assay revealed that $P$. anomala and $R$. minuta were able to secrete varying amounts of eight extracellular enzymes: cellulose, amylase, polygalacturonase, glucanase, xylanase, xylosidase, arabinofuranosidase and ferulic acid esterases. These enzymes have the capacity to degrade plant cell walls and possibly enhanced the pathogenicity of the yeasts.
\end{abstract}

Key Words: Sweet-potato, yeast, Postharvest, Pathogenicity, Ipomoea batatas

\section{Introduction}

Food spoilage may be defined as any change that renders food unfit for human consumption. Every change in food that causes it to lose its desired quality and eventually become inedible is called food spoilage or rotting. Sweet potato storage roots are subjected to several forms of postharvest deterioration in the tropical climate especially during transportation from farmers' field to market and when in storage due to mechanical injury, sprouting, weight loss, pests attack and diseases (Ray and Ravi, 2007). Sweet potato weevil is said to be the

*Corresponding Author: Kayode, R.M.O.

Email: kayodermosnr@gmail.com 
single most important storage pest in tropical regions for which no control measures or resistant variety are yet available (Ray and Ravi, 2007). Ray and Ravi (2007) reiterated that several microorganisms especially fungi have been found to induce spoilage in stored sweet potatoes. Some important species that were mentioned by Ray and Ravi (2007) include Botryodiplodia theobromae, Ceratocystis fimbriata, Fusarium spp., and Rhizopus oryzae. The authors also reported other less frequently occurring spoilage microorganisms like Cochliobolus lunatus (Curvularia lunata), Macrophomina phaseolina, Sclerotium rolfsii, Rhizoctonia solani and Plenodomus destruens (Ray and Ravi, 2007). Yeast spoilage is favoured in products with low $\mathrm{pH}$, generally 5.5 or lower, and by the presence of sugars, organic acids and other easily metabolized carbon sources (Covadonga et al., 2002).Microbial attack of stored food is a limiting factor in determining the shelf life of fruits and vegetables. The presence and growth of yeasts in food may cause spoilage resulting in a reduction in quality and quantity. Sweet potato and some other important food crops such as tomatoes, bananas and pears are attacked by yeasts particularly in storage (Kelman, 1984).Invasive infections have been linked with the presence of these organisms in foods and their residual toxins represent a threat to human health (Philips, 1984).Although the loss of food calories and nutritional elements are rightfully a major concern of the international food agencies, mycotoxins and toxic stress metabolites in food colonized by microorganisms have been recognised as a major dietary problem and is of key concern in developing countries (Philips, 1984). Symptoms of some of these diseases in the root tubers include colour changes on the skin surface usually with brown or black patches, change in texture with the tuber becoming very hard or appearing dry and mummified. Off-odours and off-flavours may also result causing deterioration of quality and reduction in shelf-life (Guerzoni et al., 1996). Presently there is dearth of information on the enzyme activities of organisms isolated from decomposing sweet potato. Therefore, this study is designed to isolate, identify and also investigate the enzyme activities of yeasts associated with the spoilage of sweet potato (Ipomea batatas).

\section{Materials and Methods}

Two kilogrammes of fresh healthy sweet potato samples were obtained from the market in Offa town, Oyun Local Government Area, Kwara State, Nigeria. The samples were transported in sterile containers for further analysis at the laboratory of the Department of Food Sciences, School of Biosciences, The University of Nottingham, Sutton Bonington Campus, Loughborough.

\section{Storage of Samples}

Samples were distributed into sterile plastic containers and stored at either $13^{\circ} \mathrm{C}$, $21^{\circ} \mathrm{C}$ or $29^{\circ} \mathrm{C}$ for a period of four weeks.

Isolation and Identification of Yeast

Potato Dextrose Agar (PDA) (Oxoid, UK) was used for the isolation yeasts. According to the manufacturer's specificities, PDA is a suitable medium for the isolation and count of yeasts and moulds occurring on foods (American Public Health Association, 1992). At the end of each week, samples were taken from the incubators for microbiological analysis. Two sets of serial dilutions $\left(10^{-1}\right.$ to $\left.10^{-9}\right)$ were prepared using both the surface peel and the deep tissue cored from the samples.

\section{Inoculation of Samples}

Volumes of $0.1 \mathrm{ml}$ of each of the diluents were aseptically transferred on to potato dextrose agar plates in triplicate. A sterile spreader was then used to spread the inoculums over the surface of the agar plate. After inoculation, the PDA plates were 
incubated at $25^{\circ} \mathrm{C}$ for 1-3 days and yeast growth assessed every 24 hours.

\section{Determination of Microbial Counts}

Potato Dextrose Agar (PDA) (Oxoid, UK) was used for the enumeration yeasts in the samples. At the end of the incubation period, culture plates with colonies having between 10 and 100 discrete growth foci were selected for counting. The figures obtained were thereafter expressed as colony forming unit (cfu) per gram (g). From the mixed cultures, sub-culturing was repeated until distinct axenic cultures were obtained.

\section{Gram Staining of Yeasts Isolates}

Single colonies from each of the culture plates were aseptically picked and stained. The slide was viewed on the light microscope with oil immersion objective. Photographs of the stained slides were collected and stored electronically.

Extraction of Deoxyribonucleic acid (DNA) from Yeast

Yeast DNAs were extracted according to the method of Connerton (1994). Each yeast isolate was grown overnight in $10 \mathrm{ml}$ Sabouraud Dextrose Broth (SDB), from which $4 \mathrm{ml}$ of the culture was inoculated into a fresh $10 \mathrm{ml} \mathrm{SDB}$ and incubated at $25^{\circ} \mathrm{C}$ for 3 hours. One point five (1.5) millilitres aliquots of this culture were measured in duplicate centrifuge tubes and spun down in succession at $12,500 \mathrm{~g}$ for 30 seconds in a microcentrifuge. The pellet obtained was washed once in water. After washing, the pellet was re-suspended in $0.8 \mathrm{ml}$ of sorbitol (1M) mixed with $25 \mu$ l lyticase $(10 \mathrm{mg} / \mathrm{ml}$; Sigma-Aldrich, United Kingdom) before incubation at $37^{\circ} \mathrm{C}$ for 45 minutes. After incubation, the spheroplasted cells were centrifuged at 12,500g for 2 minutes, and resuspended in $0.4 \mathrm{ml}$ ice-cold sorbitol solution, to which $45 \mu 1$ of $20 \%$ Sarkosyl was added to lyse the cells. Immediately after lysis $50 \mu \mathrm{l}$ of $1 \mathrm{M}$ Tris- $\mathrm{HCl}(\mathrm{pH} 8.0)$ and 50 $\mu l$ cold saturated phenol were added. The mixture was gently agitated on a wind mill rota in the cold room for 5 minutes. To this $50 \mu 1$ of chloroform was added and agitated for another 5 minutes on the wind mill rota in the cold room. Centrifugation was again done at $12,500 \mathrm{~g}$ for 5 minutes. Chloroform extraction was repeated twice. This was followed by another extraction with $500 \mu \mathrm{l}$ of ethyl ether. This was also done twice. Afterwards, $50 \mu \mathrm{l}$ of $2.5 \mathrm{M} \mathrm{NH}_{4} \mathrm{Ac}$ and $300 \mu \mathrm{l}$ of propan-2-ol were added to precipitate the DNA. Final centrifugation was done at $12,500 \mathrm{~g}$ for 5 minutes at room temperature, dried under vacuum and stored in the cold room.

Polymerase Chain Reaction (PCR) Amplification of Yeast Genomic DNA

PCR reactions were carried out according to James and Jack (2000) and Cocolin et al. (2002). A master mix of $50 \mu \mathrm{l}$ (final volume) was prepared as follows: $4 \mu 12.5 \mathrm{mM} \mathrm{MgCl}_{2}$, $2 \mu 10.25$ mMdNTPs, $5 \mu l$ 10x PCR buffer, 4 $\mu 1$ forward primer NL1 $(100 \mathrm{pmol} / \mu \mathrm{l}$ or 0.1 mM stock: 5'- GGC CAT ATC AAT AAG CGG AGG AAA AG - 3'), $4 \mu$ l reverse primer LS2 (100 pmol/ $\mu 1$ or $0.1 \mathrm{mM}$ stock: $5^{\prime}-$ ATT CCC AAA CAA CTC GAC TC- 3') (Cocolinet al., 2002). Ten $\mu 1$ genomic DNA template, $2 \mu \mathrm{l}$ 5U Taqpolymerase (Sigma, $\mathrm{UK}$ ) and $4 \mu \mathrm{l}$ sterile Reverse Osmosis (RO) water. The reagents were combined and heated in a thermal cycler at $94^{\circ} \mathrm{C}$ for 2 minutes. Thirty-five cycles of PCR were then performed by using $94^{\circ} \mathrm{C}$ for 10 seconds, and $72^{\circ} \mathrm{C}$ for 30 seconds, followed by $72^{\circ} \mathrm{C}$ for 2 minutes. From this $5 \mu \mathrm{l}$ of the PCR products were electrophoresed in a $1 \%$ agarose gel for 3 hours. The primers amplify the D1 region of the 26S rDNA.

\section{Sequencing of Purified Yeast DNA-PCR Products}

Aliquots of $20 \mu \mathrm{l}$ of each of the purified PCR products amplified from yeast DNA were transferred into PCR tubes labelled with the appropriate bar codes. These were then sent to MWG Biotech in Germany for DNA sequencing using the amplification primers. 
Afterwards, the nucleotide sequences of isolates were matched with existing sequence databases using the Basic Local Alignment Search Tool (BLAST) to identify the isolates based on query coverage and maximum identity in the databases. Identification was further confirmed by the use of the DISTANCE TREE matching.

\section{Infection of Sweet Potato Tubers}

The ability of the yeast isolates to establish infection (pathogenicity) and cause spoilage was determined according to Ikediegwu and Ejale (1980) and Ekundayo and Daniels (1973) including the modifications incorporated below. Fresh healthy sweet potato tubers were surface sterilized in $10 \% \mathrm{v} / \mathrm{v}$ sodium hypochlorite solution for 1 hour. They were then rinsed with six changes of sterile RO water to remove the residual effect of sodium hypochlorite. A sterile $5 \mathrm{~mm}$ cork borer was used to remove cylindrical cores $(1 \mathrm{~cm})$ from the middle portion of the tuber. Each well was inoculated with $100 \mu$ l of each of the inoculums $\left(10^{-4}-10^{-9}\right)$. The cores were immediately replaced and sealed off with sterile petroleum jelly. Some cores were inoculated with MRD $(100 \mu \mathrm{l})$ to serve as control. Alternatively tubers were cut into slices and either surface sterilized, rinsed with six changes of sterile RO water and inoculated with each of the isolates, or inoculated with the isolates without surface sterilization. After inoculation, the tubers and the slices were distributed into sterile plastic containers and sterile Petri-dishes respectively and incubated at $13{ }^{\circ} \mathrm{C}, 21^{\circ} \mathrm{C}$ and $29^{\circ} \mathrm{C}$. The sweet potato tubers and slices were inspected weekly and photographic evidence recorded

\section{Pathogenic Potentials of the Yeast Isolates}

The pathogenic or spoilage potentials of the isolated yeasts on sweet potato tubers were investigated. Inoculums from the isolates were used to infect fresh sweet potato tubers as described in the materials and methods. Inoculums were performed using triplicate tubers. After inoculation, the samples were stored at three different temperatures of $13^{\circ} \mathrm{C}, 21^{\circ} \mathrm{C}$ and $29^{\circ} \mathrm{C}$ for 4 weeks. The tubers were inspected weekly and at the end of the storage period, samples were collected from the sites of infection and analyzed as detailed earlier (see materials and methods). The majority of the isolates showed clear evidence of infection of both the whole tuber and slices when the site of inoculation was compared with the control site. Two of the yeasts Pichia anomala (PDASP14) and Rhodotorula minuta (PDADC4) were selected for further investigations based on the clear ability to spoil the tubers.

\section{Enzyme Studies}

The activities of nine different enzymes were investigated. Each of the selected yeast isolates was first grown in Sabourauddextrose medium supplemented with glucose $2 \%(\mathrm{w} / \mathrm{v})$ for 3-5 days in a shaking incubator at $25^{\circ} \mathrm{C}$. This was then transferred into fresh Sabouraud medium supplemented with $2 \%$ (w/v) mashed sweet potato and grown in a shaking incubator for 9 days at $25^{\circ} \mathrm{C}$. Daily, aliquots of the culture medium was collected and centrifuged at $13000 \mathrm{~g}$ for 5 minutes. The supernatant was carefully withdrawn while the sediment was discarded. The supernatant served as the crude secreted enzyme extract. A similar volume of the supernatant was boiled in a water bath for 10-20 minutes and used as a denatured protein control for the enzyme assays.

\section{Results}

From the PCR amplifiers of the 26S rDNA genes in the yeast isolates, the query coverage and maximum identity in the databases, fifteen yeast isolates were identifiable on the spoilt potato samples namely: Pichia guilliermondii, Sporobolomyces

Saccharomycopsis marcillae, fibuligera, 
Sporobolomyces marcillae, Pichia anomala, Rhodotorula minuta, Pichia guilliermondii, Rhodotorula minuta, Pichia guilliermondii, Sporobolomyces sp., Pichia guilliermondii, Rhodotorula minuta, Pichia guilliermondii, Rhodotorula minuta and Rhodotorula minuta (Table 1).Although, the majority of the isolates showed clear evidences of infection of both the whole tuber and slices when the site of inoculation was compared with the control site. But two of the yeasts namely: Pichiaanomala (PDASP14) and Rhodotorula minuta (PDADC4) were selected for enzyme studies based on the clear ability to spoil the tubers and the maximum identity, and recoverable potential of the yeasts isolates from infected sweet potato samples as shown in Table 2.

Table 1: Yeasts identified from the sequences obtained and from the subsequent blast and distance tree matching

\begin{tabular}{lcl}
\hline Isolate & \% Maximum Identity & Organism identified \\
\hline PDADCA & 100 & Pichia guilliermondii \\
PDASP7 & 100 & Sporobolomyces marcillae \\
PDADC2A & 96 & Saccharomycopsis fibuligera \\
PDASP4B & 99 & Sporobolomyces marcillae \\
PDASP14 & 98 & Pichia anomala \\
PDADC2B & 99 & Rhodotorula minuta \\
PDASPB & 100 & Pichia guilliermondii \\
PDASP1 & 100 & Rhodotorula minuta \\
PDASS1C & 99 & Pichia guilliermondii \\
PDASS2 & 100 & Sporobolomyces sp. \\
PDASP12 & 100 & Pichia guilliermondii \\
PDADC4 & 99 & Rhodotorula minuta \\
PDASP4A & 100 & Pichia guilliermondii \\
PDADC20 & 96 & Rhodotorula minuta \\
PDASP22 & 98 & Rhodotorula minuta \\
\hline
\end{tabular}

From the result of enzyme activity obtained in Figures 1 and 2, It is evidenced that the selected yeasts namely Pichia anomala (PDASP14) and Rhodotorula minuta (PDADC4) have the capacity to secret plant cell wall degrading enzymes on sweet potato especially when the isolates were grown in Sabouraud broth medium supplemented with $2 \%(\mathrm{w} / \mathrm{v})$ mashed sweet potato for 9 days.

The result of the investigation of the activities of enzymes in the selected yeast isolates revealed high activities for secreted glucanase. In the yeast Pichia anomala, glucanase activity was observed $24 \mathrm{~h}$ after inoculation in the culture with sweet potato (11.0 $\mu / \mathrm{mg})$ and thereafter showed considerable variation by day $2(2.0 \mu / \mathrm{mg})$, day $3(6.0 \mu / \mathrm{mg})$, days 4 to $7(3.0-1.0 \mu / \mathrm{mg})$, day $8(5.0 \mu / \mathrm{mg})$ and day $9(1.0 \mu / \mathrm{mg})$, possibly cycling in response to secondary substrate availability. Glucanase activity in Rhodotorula minuta also varied from 7.0 $\mu / \mathrm{mg}$ on day 1 before declining from days 2 to $6(2.0 \mu / \mathrm{mg})$ and subsequently increased on days 7 to $9(3.0-4.0 \mu / \mathrm{mg})$.

Xylanase activity appeared in the culture supernatants of all the organisms after $24 \mathrm{~h}$ of growth which declined after day 3 . Xylosidase activity that contributes to the utilisation of hemicelluloses by acting either post endo-xylanase activity or directly upon side chains of arabinoxylan was observed in Rhodotorula minuta on day 1 , but gradually 
declined from day 2 to 9 . contain the necessary substrates to induce Arabinofuranosidase activities in Pichia this enzyme class. Sweet potato tubers are, anomala remained at medium levels throughout the period of measurements between $10 \mu / \mathrm{mg}$ and $38 \mu / \mathrm{mg}$.

Ferulic acid esterases activity was maintained at a relatively low level throughout the investigation period in all the organisms tested. Sweet potato may not however, known to be rich in starch and therefore a good potential substrate for amylase production. Amylase production was evident between days 1 to 3 ( 2 to $12 \mu / \mathrm{mg}$ ) in all the organisms tested; however, they did not reach the activities of the cellulases before declination to lower levels by day 4 .

Table 2: List of recovered yeasts isolates from infected sweet potato samples

\begin{tabular}{lcl}
\hline Isolate & Percent Maximum Identity & Organism recovered \\
\hline PDASP14 & 100 & Pichiaanomala \\
PDADC4 & 100 & Rhodotorulaminuta \\
\hline
\end{tabular}

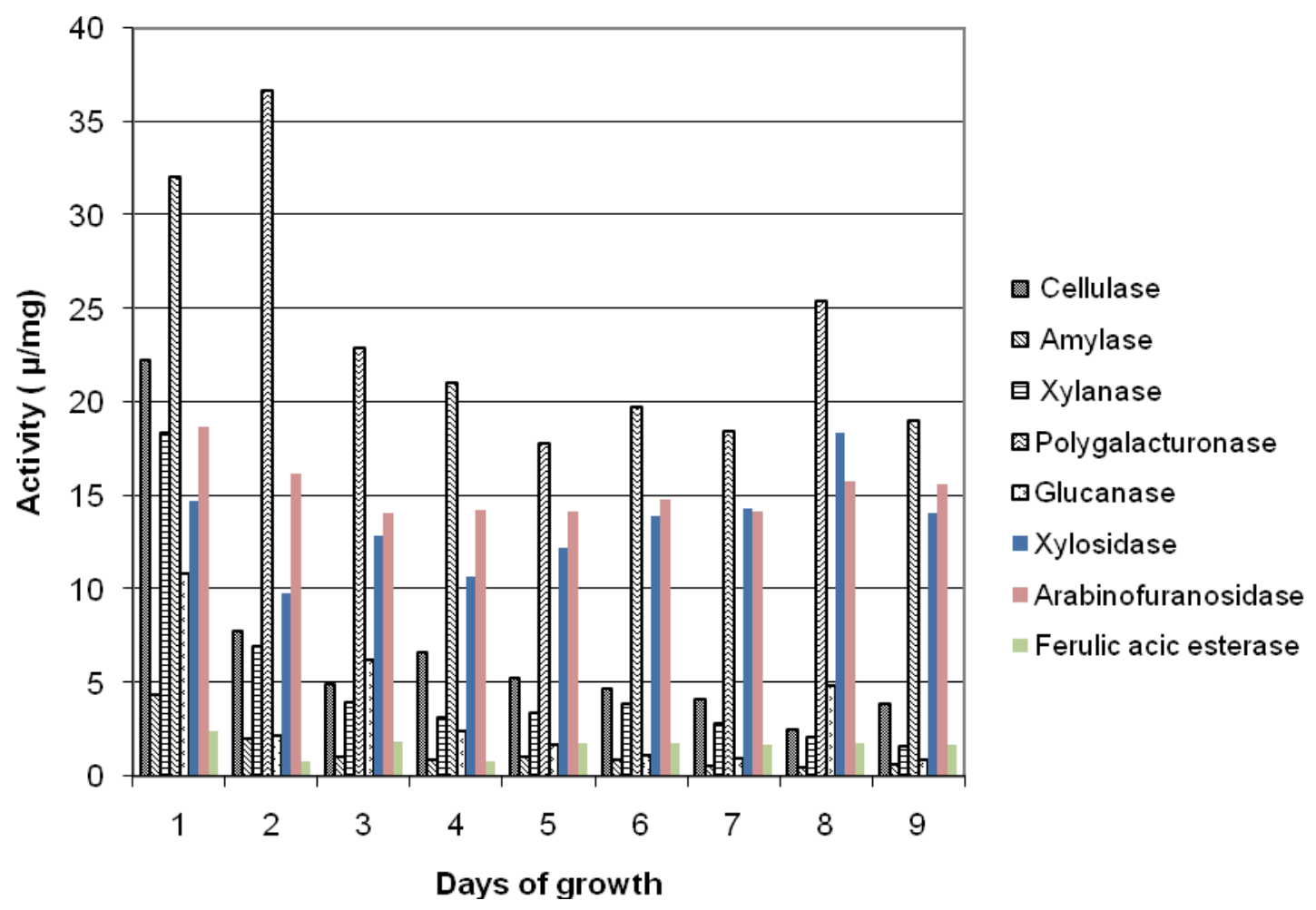

Figure 1: Enzyme activities $(\mu / \mathrm{mg})$ detected in culture supernatants of Pichia anomala (PDASP14) grown in sabouraud-dextrose medium supplemented with $2 \%(\mathrm{w} / \mathrm{v})$ mashed sweet potato as a function of the incubation time (1-9 days). 


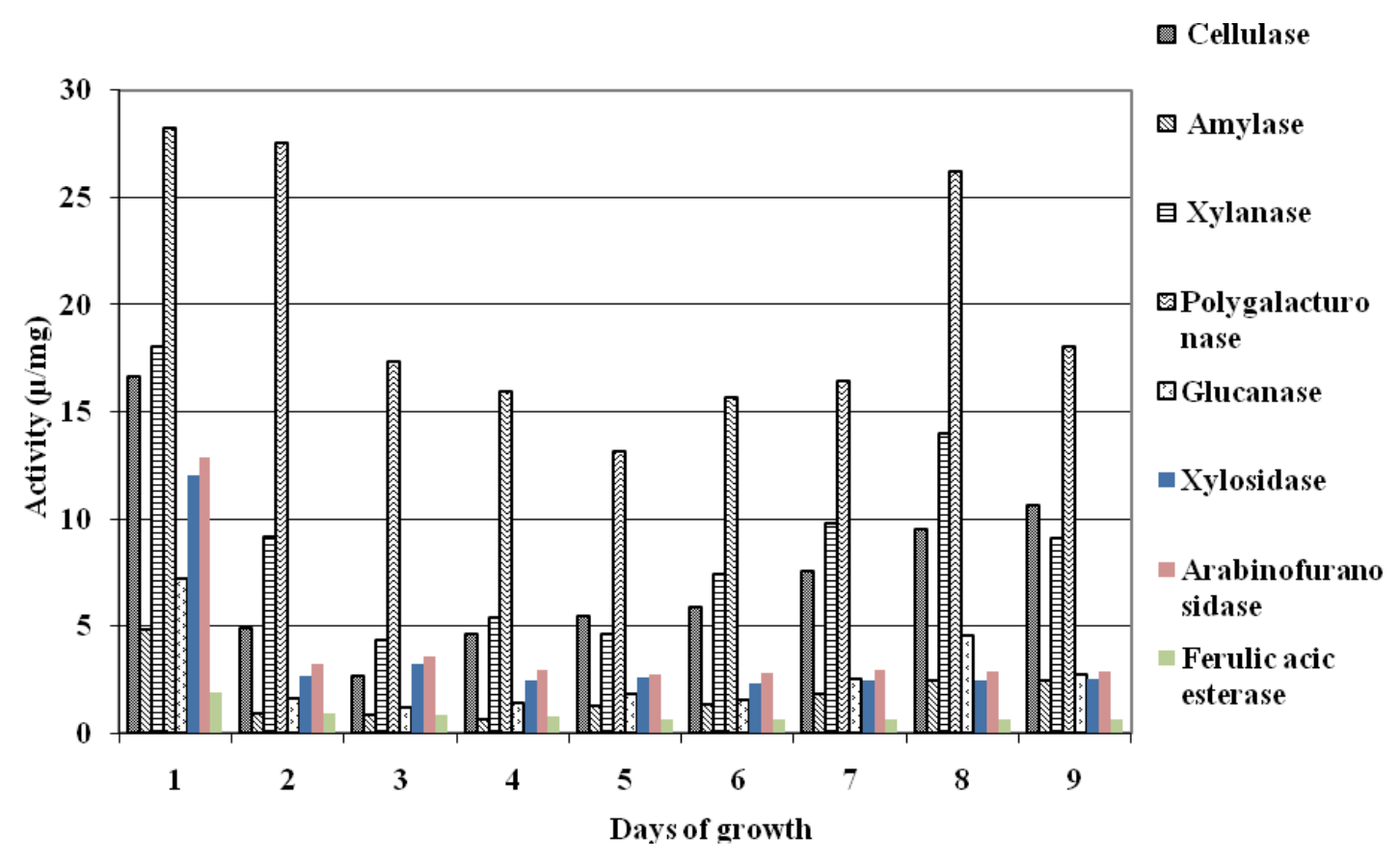

Figure 2: Enzyme activities $(\mu / \mathrm{mg})$ detected in culture supernatants of Rhodotorula minuta (PDADC4) grown in sabouraud-dextrose medium supplemented with $2 \%(\mathrm{w} / \mathrm{v})$ mashed sweet potato as a function of the incubation time (1-9 days).

\section{Discussion}

The range of yeast isolates supports earlier results, which implicate yeasts as spoilage agents of food materials in storage (Clark, 1992).

Yeasts were isolated from both the surface peel and the deep tissue of stored sweet potato. Results revealed infection in the deep tissue as well as on the surface of the tuber. This suggests that these spoilage yeasts once they can successfully colonize the surface of the tuber, they proceed into the deep tissue to cause tissue spoilage. Reports have shown that these organisms are assisted by the enzymes they secrete.(Ray, 2004).

Pichiaanomala (PDASP14) and Rhodotorula minuta (PDADC4) which were selected for enzyme studies based on the clear ability to spoil the potato tubers indicated that these organisms can secrete extra cellular enzymes into their substrates which may inturns assist them in the assimilation of nutrients that results in spoilage. The production of extra-cellular hydrolytic enzymes and in particular cellulolytic and pectinolytic enzymes capable of breaking down storage tubers has been reported (Ray, 2004). In this work, Rhodotorula minuta (PDADC4) and isolates of Pichia anomala (PDASP14) produced among others, pectinases in Sabouraud dextrose broth supplemented with sweet potato mash. This further confirms earlier reports on the production of cellulolytic and pectinolytic enzymes by several species of yeasts associated with soft rots in tuber crops (Chesson, 1980).

The storage temperatures at which these organisms grew and caused spoilage in the tubers $\left(13-29^{\circ} \mathrm{C}\right)$ also revealed that many of these organisms are capable of growing and 
causing spoilage at a range of temperatures as high as $29^{\circ} \mathrm{C}$.

Spoilage caused by Rhodotorula species has been reported in heat treated apple sauce, strawberries and cut potato chips packaged in 97-99.8\% carbon dioxide (Carbon IV oxide) (Pitt and Hocking, 2009). In these studies Rhodotorula minuta produced high initial cellulase activities on day $1(7.0 \mu / \mathrm{mg})$ and then declined on days 2 and $3(3-5 \mu / \mathrm{mg})$ which seems to quickly recover and immediately increased from days 4 to 9 (4-11 $\mu / \mathrm{mg}$ ). Pitt and Hocking (2009) reported glucanase activity in Rhodotorula minuta produced in response to plant tissues, and according to Dennis and Buhagiar (1980) (Old Ref $\}$ many species of Rhodotorula are known to produce polygalacturonases that can cause spoilage of fresh and processed fruits and vegetables.

The production of extracellular enzymes by various yeasts has been widely reported. It is generally believed that these enzymes work together in synergy complementing the efforts of one another in the degradation of plant tissues. However, the role of $P$. anomala in the spoilage of sweet potato has not been reported before this report. Ray and Byju (2003) reported that Pichia anomala was not pathogenic on sweet potato. However, in this work, we were able to establish the factthat Pichia anomala produced extracellular enzymes found to be associated with the spoilage of sweet potato and was actually found to be pathogenic on sweet potato.

Several workers have shown that causal organisms of soft rot produce cellulolytic enzymes in addition to pectinases (Obi and Moneke, 1986). Haissam and Phillipe (1997) reported the production of exo- glucanases by Pichia anomala isolated from the surface of apple. According to Chesson (1980) the yeasts causing storage rots in food crops (including sweet potato) produce rots by virtue of their pectinolytic enzyme activities which cause cell separation resulting in maceration and tissue disintegration.

\section{References}

American Public Health Association (1992). Compendium of Methods for the Microbiological Examination of Foods. $3^{\text {rd }}$ Edition. APHA Inc. Washington DC.

Cocolin, L., Aggio, D., Manzano, M., Cantoni, C. and Comi, G. (2002). An application of PCR-DGGE analysis to profile the yeast populations in raw milk. International Dairy Journal, 12: 407-411.

Clark, C.A. (1992). Postharvest diseases of sweet potatoes and their control. Postharvest News, 3: 75-79.

Connerton, I. (1994). Preparation of DNA from Saccharomyces cervisiae. An Experimental Protocol.

Covadonga, R.A., Jacqueline, K.B., Lorrie, M.F., Renee, M.G. and Mickey, E.P. (2002). Yeast Species Associated with Orange Juice: Evaluation of Different Identification Methods. Journal of Applied and Environmental Microbiology, 68: 1955-1961.

Ekundayo, J.A. and Daniel, T.M. (1973). Cassava rot and its control. Transactions of the British Mycological Society, 61: 27-32.

Guerzoni, M.E., Gianotti, A., Corbo, M.R. and Sinigaglia, M. (1996). Shelf-life Modelling For Fresh-cut Vegetables. Post Harvest Biology and Technology, 9:195-207.

Haissam, J. and Philippe, L. (1997). Characterrization of an exo- $\beta-1,3-$ glucanase produced by Pichia anomala strain K, antagonist of Botrytis cinerea on apples. Biological Control, 4: 335343.

Ikediegwu, E.O. and Ejale, A.U. (1980). Root surface mycoflora of cassava (Manihot 
esculenta) and post harvest rot of the tubers. Mycopathologia, 71:67-71.

Inacio, J., Behrens, S., Fuchs, B.M., Funseca, A., Spencer-Martins, I. and Amann, R. (2003). In Situ Accessibility of Saccharomyces cerevisiae $26 \mathrm{~S}$ rRNA to Cy3-Labeled Oligonucleotide Probes Comprising D1 and D2 Domains. Journal of Applied and Environmental Microbiology, 2899-2905.

James, B. and Jack, H.R. (2000). PCR primers that amplify fungi rRNA genes from environmental samples. Applied and Environmental Microbiology, 66: 4356-4360.

Kelman, A. (1984). Postharvest pathology of fruits and vegetables: Postharvest losses in perishable crops. Univ. Calif. Agric. Exp. Sta. Bull., 1914.80

Obi, S.K.C. and Moneke, A.N. (1986). Pectinolytic and Cellulolytic Enzymes complex of fungi associated with soft rot of yams (Dioscorea rotundata Poir). International Biodeterioration, 22: 4.

Pitt, J.I. and Hocking, A.D. (2000). Fungi and food spoilage. Academic Press, Sydney, Australia. 357-382.

Ray, R.C. (2004). Cellulolytic enzymes production in cultures and fungiinfected sweet potato roots. Annals of Tropical Research, 23: 34.

Ray, R.C. and Byju, G. (2003). Root surface culturablemicroflora associated with postharvest spoilage of sweet potato (Ipomea batatas L.). Advances in Horticultural Science, 17:176-180.

Ray, R. C. and Ravi, V. (2007). Post-Harvest Spoilage of Sweet potato in Tropics and Control Measures: In Critical Reviews in Food Science and Nutrition, 45:623644. 